\title{
Pelatihan "Perencanaan Lanjut Studi" (PLANS) terhadap Efikasi Diri dalam Pengambilan Keputusan Karier pada Siswa SMP
}

\section{"Perencanaan Lanjut Studi" (PLANS) Training on Self-Efficacy in Career Decision-Making of Lower Secondary School Student}

\author{
Yuli Rahmawati ${ }^{1}$, Fauzan Heru Santhoso ${ }^{2}$ \\ 1,2Fakultas Psikologi Universitas Gadjah Mada

\begin{abstract}
Preliminary study showed that there were some students (grade 9) who had difficulty in making career choice. The study's objective was to determine the effectiveness of "PLANS" in improving career decision-making self-efficacy. This quasi experiment was conducted using the untreated control group design with dependent pretest and posttest. The subjects were 84 students of grade 9, who had medium score in career decision-making self-efficacy (42 students of experiment group and 42 students of control group). Data was analyzed using mixed ANOVA, because it combined two sub-analysis which is within subject test and between subject test. The result showed that career decision-making self-efficacy score of experiment group is higher than control group ( $F=37,015 ; p<0.01)$. The "PLANS" training contributed $67 \%$ of career decision making self-efficacy improvement. The "PLANS" provides opportunities to gain cognitive skills and establish new behavior by making observation of other's performance.
\end{abstract}

Keywords: self-efficacy; career decision-making; career guidance

Abstrak. Permasalahan di lapangan menunjukkan bahwa sejumlah siswa kelas IX Sekolah Menengah Pertama (SMP) merasa ragu dalam menetapkan pilihan studi lanjut. Tujuan penelitian ini adalah menguji efektivitas "PLANS" untuk meningkatkan efikasi diri siswa dalam pengambilan keputusan karier. Eksperimen kuasi ini dilakukan dengan the untreated control group design with dependent pretest and posttest samples using double pretest. Subjek penelitian merupakan siswa kelas IX sejumlah 84, dengan skor efikasi diri dalam pengambilan keputusan karier tergolong sedang (42 siswa kelompok eksperimen dan 42 siswa kelompok kontrol). Mixed ANOVA dipilih karena menggabungkan dua sub-analisis yakni within subject test dan between subject test. Hasil analisis menunjukkan bahwa terdapat perbedaan skor efikasi diri dalam pengambilan keputusan karier sebelum dan setelah diberi perlakuan pada kelompok eksperimen $(F=37,015 ; p<0,01)$. Pelatihan "PLANS" memberikan kontribusi terhadap peningkatan efikasi diri dalam pengambilan keputusan karier sebesar 67\%. Pelatihan "PLANS" memberikan kesempatan pada individu untuk memperoleh keterampilan kognitif serta perilaku baru melalui pengamatan terhadap performansi orang lain.

Kata kunci: efikasi diri; pengambilan keputusan karier; perencanaan karier

${ }^{1}$ Korespondensi mengenai artikel ini dapat dilakukan melalui 1

ªtau fauzan@ugm.ac.id 
Berdasarkan data dari siaran pers Kementerian Riset, Teknologi, dan Pendidikan Tinggi (Kemenristekdikti) (2018) nomor: 48/SP/HM/BKKP/IV/2018, Indonesia merupakan salah satu negara dengan profil demografis termuda di dunia dengan lebih dari 138 juta (53,5\%) penduduk Indonesia yang berusia di bawah 30 tahun. Angka partisipasi kasar (APK) pendidikan tinggi Indonesia saat ini baru mencapai 31,5\%, dan berdasarkan penelitian yang dilakukan oleh Youthmanual (Kemenristekdikti, 2018) terhadap 400.000 siswa SMA/SMK dan mahasiswa dalam kurun waktu dua tahun ditemukan fakta bahwa 92\% siswa SMA/SMK sederajat bingung dan tidak tahu akan menjadi apa kedepannya. Selain itu, 45\% mahasiswa merasa salah mengambil jurusan.

Menurut penelitian Youthmanual tersebut terdapat tiga penyebab utama yang membuat calon mahasiswa sering salah jurusan, di antaranya adalah (1) Prestigeoriented, banyak siswa yang beranggapan bahwa bila tidak berkuliah di jurusan $X$ yang banyak peminatnya maka tidak keren atau bila tidak berkuliah di kampus $\mathrm{Y}$ disebut kurang gaul. Prestige-oriented ini juga dapat dipengaruhi orang tua, di mana orang tua biasanya memaksa anaknya untuk masuk jurusan tertentu dengan alasan prospek kerja yang lebih baik di masa depan. (2) Kurang riset, riset jurusan juga diperlukan dalam menentukan jurusan di jenjang perkuliahan. Riset ini berguna agar siswa dapat memperkirakan jurusan mana yang lebih cocok untuknya. Riset juga berguna untuk mendapatkan informasi seputar jurusan, seperti passing grade, mata kuliah, serta profesi apa yang dapat ditekuni setelah lulus. (3) Tidak menggali minat dan bakat sejak dini, mengenali bakat dan minat sejak dini dapat membantu siswa dalam menentukan jurusan kuliah. Mengenali diri sendiri dapat diperoleh dengan banyak mengeksplorasi berbagai kegiatan yang disenangi dan dikuasai. Memilih jurusan sesuai dengan bakat dan minat sangat penting karena siswa dapat menjadi lebih gembira, dan tidak merasa terbebani saat menjalani proses kuliah.

Penelitian tersebut menekankan bahwa permasalahan utama bagi siswa adalah siswa tidak mengenal diri dan potensi yang dimiliki. Terlebih lagi, siswa kurang mendapat panduan, informasi terkini terkait beragam bidang, peta karier, dan dinamika industri saat ini, di mana muncul banyak sekali profesi-profesi dan program studi baru yang dibutuhkan industri. Sekolah Menengah Pertama (SMP) diharapkan mampu merencanakan pilihan jurusan di bangku kuliah dan karier di masa depan sejak dini, sehingga mereka dapat menentukan akan memilih jurusan Bahasa, MIPA, atau IPS di bangku SMA. Sekolah Menengah Pertama adalah saat yang tepat untuk merencanakan karier dan jurusan kuliah (Gibbsons \& Borders, 2010). Menurut Hossler, Schmit, \& Vesper (Gibbsons \& Borders, 2010) pilihan karier yang dibuat jauh sebelum lulus SMA cenderung akan lebih stabil. Siswa biasanya akan membuat keputusan terkait pendidikan mereka di masa depan pada tingkat 8 sampai 10, dan keputusan tersebut secara langsung memengaruhi persiapan berkuliah serta 
tingkat kehadiran kuliah di masa depan (Atanda, 1999).

Dewasa ini, menentukan karier untuk masa depan menjadi lebih sulit karena pilihan karier yang semakin banyak dan beragam. Menurut Gati et al. (dalam Storme \& Celik, 2018), kesulitan mengambil keputusan karier mengacu pada tantangan yang dialami individu ketika proses membuat keputusan terkait karier, misalnya seperti memilih jurusan pendidikan. Storme \& Celik (2018) berpendapat bahwa lingkungan karier saat ini menghadirkan peluang baru yang lebih menantang bagi individu, dan eksplorasi karier memerlukan tingkat kepercayaan diri yang relatif tinggi, terkait kemampuan individu yang secara kreatif mengintegrasikan pilihan yang tersedia ke jalur karier yang baru.

Pengambilan keputusan karier pada siswa dipengaruhi oleh beberapa faktor, seperti faktor personal, faktor kelompok, faktor sekolah, dan faktor eksplorasi karier (Su, Chang, Wu, \& Liao, 2016). Faktor personal memengaruhi pengambilan keputusan karier siswa pada tiga aspek, yakni motivasi belajar, sikap belajar, dan efikasi diri. Faktor kelompok memengaruhi pengambilan keputusan karier siswa pada dua aspek, yaitu ekspektasi orang tua terkait pendidikan, serta sikap orang tua terhadap pendidikan. Faktor ketiga yang memengaruhi pengambilan keputusan karier siswa yaitu faktor sekolah, di mana faktor sekolah ini memiliki dua aspek, seperti ekspektasi guru, dan pengaruh teman sebaya. Faktor keempat yang memengaruhi pengambilan keputusan karier siswa adalah faktor eksplorasi yang memiliki tiga aspek, yaitu sikap guru terhadap pendidikan, lingkungan dan saranaprasarana belajar, serta model dan pelaksanaan pembelajaran.

$$
\text { Penelitian ini berfokus pada }
$$

peningkatan efikasi diri siswa dalam pengambilan keputusan karier, karena menurut penelitian Su et al. (2016) bahwa keputusan karier pada siswa sekolah menengah pertama (SMP) yang paling utama dipengaruhi oleh faktor personal seperti motivasi belajar, sikap belajar, dan efikasi diri. Efikasi diri dapat digunakan untuk membantu mengidentifikasi potensi serta pilihan karier yang akan diambil (Betz \& Wolfe, 2005). Penelitian terdahulu yang dilakukan oleh Beghetto (2016) juga menunjukkan bahwa individu dengan efikasi diri yang tinggi cenderung memiliki keyakinan yang lebih positif terhadap kemampuan akademis mereka di berbagai bidang studi, dan secara signifikan menunjukkan rencana untuk berkuliah, dibandingkan individu yang memiliki nilai efikasi diri yang lebih rendah.

Salah satu bidang penelitian yang populer dalam psikologi adalah aplikasi teori efikasi diri Albert Bandura sebagai landasan teori dalam pengembangan karier. Penelitian Kudo \& Mori (2015) pada siswa sekolah menengah pertama (SMP) menunjukkan bahwa enactive mastery experience sebagai salah satu faktor yang dapat meningkatkan efikasi diri. Efikasi diri sebagai faktor yang dapat ditingkatkan inilah yang kemudian menjadi alasan utama pelatihan "PLANS" digunakan dalam penelitian ini. Pelatihan Perencanaan Lanjut Studi ("PLANS") 
merupakan pelatihan perencanaan karier yang disusun berdasarkan teori tahapan perencanaan karier Jaffe dan Scott (1991). Kirkpatrick menyatakan bahwa pelatihan merupakan metode pembelajaran yang bertujuan untuk mengubah aspek kognitif, afektif, serta hasil keterampilan dan keahlian (Salas \& Browers, 2001). Berdasarkan hal tersebut, pelatihan "PLANS" ini digunakan dengan harapan dapat menjadi enactive mastery experience, sehingga dapat meningkatkan efikasi diri siswa dalam pengambilan keputusan karier.

Tujuan dari penelitian ini adalah untuk mengetahui apakah pelatihan "PLANS" dapat meningkatkan efikasi diri dalam pengambilan keputusan karier pada siswa sekolah menengah pertama (SMP). Subjek penelitian SMP dipilih karena masih cukup jarang diteliti. Padahal, penjurusan pendidikan sendiri sudah dimulai semenjak siswa memasuki jenjang SMA/SMK. Apabila siswa sudah "salah" memilih jurusan sejak SMA/SMK, maka dampaknya akan dirasakan hingga di masa depannya kelak (Sudira, 2013). Metode pembelajaran yang digunakan dalam pelatihan "PLANS" ini adalah konsep observational learning (belajar melalui pengamatan) yang dikemukakan oleh Bandura (1997). Melalui metode observational learning ini, individu memperoleh keterampilan kognitif serta perilaku baru melalui pengamatan terhadap performansi orang lain. Efikasi diri individu dapat meningkat melalui pengamatan teradap orang lain sebagai model, terutama apabila individu merasa memiliki kemampuan yang setara atau bahkan merasa lebih baik dari model, serta memiliki banyak kesamaan karakteristik, tingkat kesulitan tugas, dan situasi dengan model (Bandura, 1997). Berdasarkan hal tersebut, hipotesis pada penelitian ini adalah pelatihan "PLANS" dapat meningkatkan efikasi diri dalam pengambilan keputusan karier pada siswa kelas IX.

\section{Metode}

\section{Identifikasi variabel}

Variabel tergantung dalam penelitian ini adalah efikasi diri dalam pengambilan keputusan karier. Efikasi Diri Pengambilan Keputusan Karier merupakan keyakinan individu terkait kemampuan dirinya dalam mengerjakan tugas yang berkaitan dengan proses pengambilan keputusan karier. Karier yang dimaksud dalam penelitian ini adalah studi lanjut setelah lulus dari jenjang SMA, yakni pilihan program studi di perguruan tinggi. Variabel bebas dalam penelitian ini adalah Pelatihan Perencanaan Lanjut Studi (PLANS). Pelatihan Perencanaan Lanjut Studi ("PLANS") disusun oleh Ardiyanti (2014) berdasarkan lima tahap perencanaan karier oleh Jaffe and Scott (1991).

\section{Subjek}

Subjek penelitian merupakan siswa Sekolah Menengah Pertama (SMP) di Kota Yogyakarta dengan rentang usia 14 hingga 15 tahun. Pemilihan subjek untuk kelompok eksperimen dan kelompok kontrol berdasarkan hasil screening pada seluruh kelas IX menggunakan skala efikasi diri dalam pengambilan keputusan karier, yakni 
merupakan siswa yang memiliki skor efikasi diri dalam pengambilan keputusan karier dengan kategori rendah sampai sedang. Berdasarkan hasil screening tersebut didapatkan total subjek sebanyak 84 orang, yang terdiri dari 18 siswa laki-laki, dan 66 siswa perempuan. Penempatan subjek penelitian ke dalam kelompok eksperimen dan kelompok kontrol dilakukan secara acak, dengan proporsi 42 orang kelompok eksperimen dan 42 orang kelompok kontrol.

\section{Instrumen penelitian}

Data diperoleh dengan menggunakan skala Efikasi Diri Pengambilan Keputusan Karier serta menggunakan intervensi dengan pelatihan "PLANS" dan dengan Skala Efikasi Diri Pengambilan Keputusan Karier ini disusun Ardiyanti (2014) dengan berdasarkan dimensi efikasi diri Bandura, yakni level (tingkat kesulitan), generality (rentang keluasan bidang), dan strength (tingkat kekuatan). Model penskalaan yang digunakan dalam skala ini adalah summated ratings (Likert). Uji validitas isi skala dilakukan oleh professional judgement oleh dua orang psikolog. Dari 36 aitem yang diuji cobakan terhadap 163 siswa, terdapat dua aitem yang gugur karena besaran indeks daya beda kurang dari 0,30. Total aitem yang sahih berjumlah 34 aitem dengan indeks daya beda aitem berkisar 0,311-0.727. Koefisien reliabilitas skala ini dinyatakan dengan nilai alpha Cronbach sebesar 0,941 (Ardiyanti \& Alsa, 2015).

\section{Desain penelitian}

Penelitian ini adalah penelitian kuantitatif dengan metode quasi experiment, yakni the untreated control group design with dependent pretest and post-test samples using double pretest. Desain ini menggunakan kelompok perlakuan (kelompok eksperimen) dan kelompok yang tidak diberi perlakuan (kelompok kontrol) sebagai pembanding. Pretest dilakukan dua kali dalam penelitian ini. Hal ini untuk meminimalisasi adanya ancaman maturitas terhadap internal validity. Kelompok eksperimen dan kelompok kontrol akan diberikan pretest yang sama. Kelompok eksperimen akan mendapat perlakuan, sementara kelompok kontrol tidak. Setelah perlakuan, dilakukan posttest pada kelompok eksperimen dan kelompok kontrol. Kelompok kontrol kemudian akan mendapatkan perlakuan setelah penelitian selesai, dengan pertimbangan etika. Hal ini dinamakan waiting list group. Gambar 1 menunjukkan desain eksperimen yang dilakukan.

\begin{tabular}{lllll} 
KE & $\mathrm{O}_{1}$ & $\mathrm{O}_{2}$ & $\mathrm{X}$ & $\mathrm{O}_{3}$ \\
\hline $\mathrm{KK}$ & $\mathrm{O}_{1}$ & $\mathrm{O}_{2}$ & & $\mathrm{O}_{3}$
\end{tabular}

Keterangan:

KE : Kelompok eksperimen

KK : Kelompok kontrol

$\mathrm{O}_{1}$ : Pretest 1

$\mathrm{O}_{2}$ : Pretest 2

$\mathrm{O}_{3}$ : Posttest

X : Perlakuan

Gambar 1. Desain eksperimen

Intervensi

Intervensi yang diberikan berupa pelatihan perencanaan karier dengan nama Pelatihan 
"PLANS". Pemberian nama PLANS diharapkan mampu menstimulasi peserta agar berperan aktif dalam mengikuti sesi pelatihan (Ardiyanti, 2014). Modul pelatihan disusun berdasarkan lima tahap perencanaan karier oleh Jaffe and Scott. Pelatihan ini memiliki lima sesi, yakni (1) analisis diri, (2)

Tabel 2.

Statistik Deskriptif

\begin{tabular}{|c|c|c|c|c|c|}
\hline & \multicolumn{2}{|c|}{$\begin{array}{c}\text { Kelompok Eksperimen } \\
\qquad(N=42)\end{array}$} & \multicolumn{2}{|c|}{ Kelompok Kontrol $(N=42)$} & \multirow{2}{*}{$\begin{array}{c}\text { Levene's Test for } \\
\text { Equality of } \\
\text { Variances } \\
\text { Sig. }\end{array}$} \\
\hline & Mean & $S D$ & Mean & $S D$ & \\
\hline Pretest 1 & 107,69 & 6,338 & 10800 & 5,885 &, 450 \\
\hline Pretest 2 & 111,12 & 8,098 & 106,79 & 7,842 & ,588 \\
\hline Posttest & 122,83 & 8,622 & 108,12 & 6,053 & ,112 \\
\hline
\end{tabular}

wawasan karier, (3) penetapan tujuan dan perencanaan karier, (4) rencana tindakan, dan (5) evaluasi. Pelatihan ini dirancang untuk membantu meningkatkan efikasi diri dalam pengambilan keputusan karier melalui pemahaman terhadap lima tahap perencanaan karier tersebut. Penjelasan lebih rinci dapat dilihat pada Tabel 1 (hal. 88).

Trainer dalam pelatihan ini adalah mahasiswa Magister Psikologi Profesi yang telah lulus HIMPSI, memiliki pengalaman mendampingi siswa SMA dalam pemilihan jurusan di Perguruan Tinggi, dan berpengalaman memberikan pelatihan kepada siswa SMP. Co-trainer dalam pelatihan ini merupakan psikolog dan mahasiswa Magister Psikologi Profesi yang telah lulus HIMPSI dengan kualifikasi berpengalaman berinteraksi dengan siswa SMP dan mendampingi siswa SMP dalam pemilihan jurusan.

\section{Hasil}

Berdasarkan hasil analisis skor efikasi diri dalam pengambilan keputusan karier, diperoleh hasil statistik deskriptif pada Tabel 2.

Terdapat perbedaan rerata skor pretest 1 pada kelompok eksperimen dan kelompok kontrol, dengan signifikansi sebesar 0,450 > 0,05, sehingga dapat diartikan bahwa data antara kelompok eksperimen dan kelompok kontrol adalah homogen. Data kelompok eksperimen dan kelompok kontrol pada pretest 2 juga menunjukkan adanya perbedaan skor, dengan signifikansi sebesar 0,588, di mana hal tersebut berarti kelompok eksperimen dan kelompok kontrol memiliki data pretest 2 yang homogen.

Setelah dilakukan perlakuan dan pengukuran posttest, rerata skor efikasi diri dalam pengambilan keputusan karier pada kelompok eksperimen lebih tinggi, dengan mean 122,83, sedangkan mean pada kelompok kontrol adalah sebesar 108,12. Berdasarkan uraian tersebut, maka dapat disimpulkan bahwa terjadi peningkatan rerata skor efikasi diri dalam pengambilan keputusan karier pada kelompok eksperimen. Grafik 1 


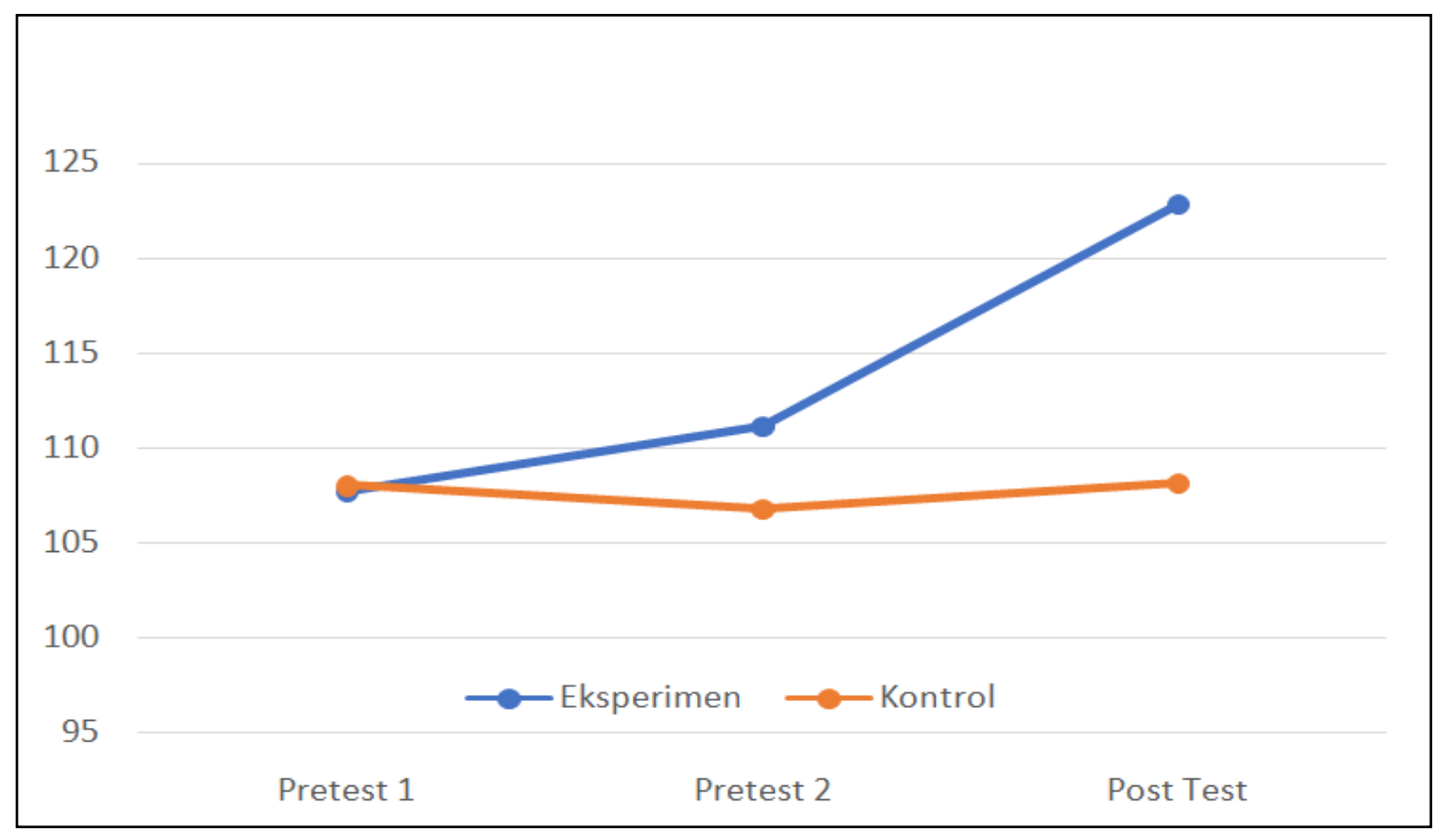

Grafik 1. Rerata skor kelompok eksperimen dan kelompok kontrol

menunjukkan perbandingan rerata skor pada kelompok (eksperimen - kontrol). Interaksi kelompok eksperimen dan kelompok kontrol, ini menunjukkan bahwa perubahan skor di mana dapat dilihat bahwa kelompok pretest menuju posttest pada kedua kelompok eksperimen memiliki skor posttest yang lebih (eksperimen-kontrol) adalah berbeda secara tinggi dibandingkan kelompok kontrol. signifikan.

Tabel 3.

Ringkasan Uji Hipotesis Within Subject

\begin{tabular}{lcccccc}
\multicolumn{1}{c}{ Sumber } & $\begin{array}{c}\text { Type III Sum of } \\
\text { Squares }\end{array}$ & $d f$ & Mean Square & $F$ & Sig. & $\begin{array}{c}\text { Partial Eta } \\
\text { Squared }\end{array}$ \\
\hline Time & 2856,484 & 2 & 1428,242 & 42,544 &, 000 &, 342 \\
Time*Kelompok & 2485,246 & 2 & 1242,623 & 37,015 &, 000 &, 311 \\
Error (time) & 5505,603 & 164 & 33,571 & & & \\
\hline
\end{tabular}

Uji hipotesis

Uji hipotesis dilakukan dengan menggunakan mixed ANOVA dengan melihat tests of within subject effects. Tabel 3 meringkas hasil analisis mixed ANOVA.

Baris time*Kelompok pada Tabel 3 menunjukkan hasil $F=37,015(p<0,01)$. Hal ini mengindikasikan adanya interaksi antara waktu (pretest 1 - pretest 2 - posttest) dengan

\section{Uji lanjutan}

Uji lanjutan dimaksudkan untuk mengetahui pasangan kelompok mana yang mengalami perbedaan dengan melihat selisih rerata skor dari tiap pengukuran pada kelompok eksperimen dan kelompok kontrol. 
Tabel 4.

Uji Lanjutan Selisih Rerata Skor dan Sumbangan Efektif

\begin{tabular}{|c|c|c|c|c|c|}
\hline Kelompok & Time (I) & Time $(J)$ & $\begin{array}{c}\text { Mean } \\
\text { Difference (I- } \\
\text { J) }\end{array}$ & Sig. & $\begin{array}{c}\text { Partial Eta } \\
\text { Squared }\end{array}$ \\
\hline \multirow[t]{3}{*}{ Eksperimen } & Pretest 1 & Pretest 2 & $-3,429$ & 010 & 667 \\
\hline & & Posttest & $-15,143$ & ,000 & \\
\hline & Pretest 2 & Posttest & $-11,714$ & ,000 & \\
\hline \multirow[t]{3}{*}{ Kontrol } & Pretest 1 & Pretest 2 & 1,214 & ,351 & ,016 \\
\hline & & Posttest &,- 119 & ,952 & \\
\hline & Pretest 2 & Posttest & $-1,333$ & ,286 & \\
\hline
\end{tabular}

Berdasarkan Tabel 4, diketahui bahwa pada kelompok eksperimen semua mean difference bertanda negatif. Hal ini mengindikasikan adanya peningkatan skor efikasi diri dalam pengambilan keputusan karier pada kelompok eksperimen. Semua peningkatan bernilai signifikan, kecuali pada peningkatan skor pretest 1 ke pretest 2. Hasil ini menunjukkan bahwa kedua skor tersebut tidak banyak mengalami perubahan. Double pretest dalam penelitian ini digunakan untuk meminimalisasi ancaman maturasi. Mean difference pada skor pretest 1 ke pretest $2(M D=$ $-3,429 ; p>0,05)$ membuktikan bahwa tidak ada efek maturasi, baik pada kelompok eksperimen maupun pada kelompok kontrol.

Skor pada kelompok kontrol juga diketahui bahwa terdapat skor yang meningkat, ada pula skor yang turun, namun semuanya tidak signifikan. Hal ini menunjukkan bahwa tidak ada perubahan skor yang berarti pada kelompok kontrol. Berdasarkan data tersebut, maka dapat disimpulkan bahwa Pelatihan Perencanaan Lanjut Studi (PLANS) dapat meningkatkan efikasi diri dalam pengambilan keputusan karier pada kelompok eksperimen secara signifikan. Sumbangan efektif pelatihan pada kelompok eksperimen dapat dilihat dari nilai partial eta squared $\eta^{2} p=0,667$. Artinya, pelatihan PLANS yang diberikan kepada kelompok eksperimen memberikan konribusi sebesar $67 \%$ terhadap perubahan efikasi diri dalam pengambilan keputusan karier.

Hasil cek manipulasi (pengetahuan perencanaan karier)

Pengetahuan tentang perencanaan karier pada partisipan penelitian diungkap dengan menggunakan tes berbentuk pilihan ganda dengan dua puluh lima pertanyaan. Skor pretest dan posttest pengetahuan tentang perencanaan karier dianalisis dengan menggunakan T-Test Independent-Samples.

Berdasarkan hasil analisis pada Tabel 5, diketahui bahwa rerata skor pretest pada kelompok eksperimen dan kelompok kontrol tidak menunjukkan perbedaan yang signifikan. Hal tersebut diketahui karena nilai sig. (2-tailed) sebesar 0,307 >0,05. Tabel 5 juga menunjukkan bahwa rerata skor pretest pada kelompok eksperimen dan kelompok kontrol merupakan data yang setara atau homogen, yang ditunjukkan dengan nilai signifikansi 
Levene's test for equality of variances sebesar $0,806>0,05$. Skor posttest pada diketahui Tabel 5.

Tabel T-Test Pengetahuan Perencanaan Karier

\begin{tabular}{lcccccc}
\hline & \multicolumn{2}{c}{ Kelompok } & Kelompok Kontrol \\
& Eksperimen $(\mathrm{N}=42)$ & & $\begin{array}{c}\text { Levene's Test for } \\
\text { Equality of } \\
\text { Variances }\end{array}$ & $\begin{array}{c}\text { T-test for } \\
\text { Equality of } \\
\text { Means }\end{array}$ \\
\cline { 2 - 7 } & Mean & SD & Mean & SD & Sig. & Sig. (2-tailed) \\
\hline Pretest & 16,78 & 2,225 & 16,30 & 2,018 &, 806 &, 307 \\
\hline Posttest & 18,66 & 2,091 & 16,57 & 2,049 &, 962 &, 000 \\
\hline
\end{tabular}

mengalami peningkatan pada kelompok eksperimen, dengan $p=0,000 \quad(p<0,01)$. Artinya terdapat peningkatan yang signifikan pada skor pengetahuan perencanaan karier pada peserta dalam kelompok eksperimen selama mengikuti pelatihan PLANS.

\section{Diskusi}

Kelompok eksperimen menunjukkan peningkatan skor efikasi diri pengambilan keputusan karier setelah diberikan perlakuan berupa Pelatihan Perencanaan Lanjut Studi (PLANS), sementara kelompok kontrol tidak mengalami perubahan yang signifikan pada skor efikasi diri pengambilan keputusan karier. Skor efikasi diri dalam pengambilan keputusan karier baik pada kelompok eksperimen, maupun pada kelompok kontrol tidak mengalami perubahan yang signifikan pada pretest 1 dan pretest 2 . Artinya, sebelum diberikan perlakuan efikasi diri dalam pengambilan keputusan karier pada kedua kelompok tidak mengalami perubahan, sehingga dapat disimpulkan bahwa validitas internal dari penelitian ini cukup terjaga, karena kedua kelompok tidak mengalami ancaman maturasi. pengambilan keputusan karier dapat dipengaruhi oleh adanya perlakuan berupa Pelatihan Perencanaan Lanjut Studi (PLANS). Berdasarkan hasil cek manipulasi, diketahui bahwa pengetahuan partisipan dalam kelompok eksperimen terkait perencanaan karier mengalami peningkatan secara signifikan setelah mengikuti pelatihan PLANS. Selama pelaksanaan pelatihan ini, partisipan pada kelompok eksperimen tidak hanya mengetahui tahapan perencanaan karier, namun juga diajak untuk mampu membuat perencanaan karier dengan mengisi worksheet yang telah disediakan. Melalui serangkaian proses yang terdapat dalam sesi pelatihan PLANS itulah, partisipan pada kelompok eksperimen menjadi lebih mampu untuk mempersepsikan bahwa pengambilan keputusan karier ini bukanlah hal yang sulit untuk dilakukan.

Teknologi yang berkembang pesat menyebabkan adanya perubahan pada beberapa bidang pekerjaan dan menghasilkan keberadaan pekerjaan baru yang membutuhkan keahlian di bidang yang baru dan berbeda, sehingga dibutuhkan kepedulian yang lebih dalam memilih karier pada zaman sekarang (Bolat \& Odaci, 2017). 
Berdasarkan perspektif sosial kognitif, pelatihan PLANS ini merupakan bagian dari faktor lingkungan yang berperan untuk memengaruhi faktor personal, yakni efikasi diri dalam pengambilan keputusan karier pada siswa (Ardiyanti \& Alsa, 2015). Pelatihan PLANS menimbulkan pengaruh terhadap efikasi diri dalam pengambilan keputusan karier pada siswa karena siswa dilibatkan secara aktif pada setiap sesi pelatihan. Hal tersebut sejalan dengan penelitian yang menyatakan bahwa konseling karier mampu meningkatkan efikasi diri dalam pengambilan keputusan karier pada mahasiswa di Cina (Wang, Zhang, \& Shao, 2010), serta penelitian Seo \& Jeong (2016) yang menemukan bahwa, program pelatihan karier pada siswa sekolah perawat mampu meningkatkan level efikasi diri dalam pengambilan keputusan karier.

Secara spesifik, pelatihan PLANS memungkinkan siswa untuk mampu mengenali dirinya sendiri, mengidentifikasi kemampuan dan minat dalam dirinya, mampu mencari informasi mengenai karier dan studi lanjutan, mampu menetapkan tujuan, membuat rencana karier, serta mampu melakukan evaluasi. Hal tersebut sesuai dengan pernyataan Leigh (2006) bahwa pelatihan perencanaan karier memungkinkan siswa untuk mengidentifikasi, mendiskusikan, merencanakan, dan mengeksplorasi tujuan karier mereka.

Pelatihan perencanaan karier sesi analisis diri memberikan keterampilan kepada siswa untuk dapat mengenali dirinya sendiri. Siswa mampu mengeksplorasi diri, dan mengetahui potensi diri melalui refleksi atas keberhasilan dan kegagalan di masa lampau, serta mengidentifikasi kelebihan dan kelemahan diri. Pengetahuan terkait diri sendiri sangat penting, karena dengan mengetahui hal tersebut siswa mampu mengidentifikasi langkah-langkah yang harus diambil untuk mencapai tujuan. Kesadaran akan minat, nilai, dan kemampuan diri sendiri dapat membantu siswa dalam memilih target yang lebih realistis dan sesuai dengan level kemampuannya, serta dapat membantu siswa untuk mengatasi hambatanhambatan dalam menentukan pilihan kariernya (Bolat \& Odaci, 2017).

Pengambilan keputusan karier juga sangat dipengaruhi oleh wawasan karier yang dimiliki individu, serta ketersediaan informasi. Pelatihan PLANS sesi kedua memberikan kesempatan bagi siswa untuk mengumpulkan informasi dan melakukan analisa atas informasi yang didapatkan dengan potensi diri dan peluang karier yang ada. Penugasan pada sesi ini memungkinkan siswa untuk mencari dan menganalisa kesesuaian antara potensi dirinya dengan berbagai alternatif pilihan karier. Siswa juga diberikan penugasan untuk mengumpulkan informasi mengenai aktivitas serta kompetensi yang dibutuhkan dalam setiap pilihan karier yang tersedia. Menurut Robbins, semakin lengkap informasi yang ada, maka akan semakin mudah bagi siswa untuk menentukan pilihan dan mengambil keputusannya (Damayanti \& Widyowati, 2018).

Efikasi diri dapat meningkat apabila target perilaku sesuai dengan kemampuan 
yang dimiliki (Bandura, 1997). Pelatihan PLANS memberikan keterampilan bagi siswa untuk mampu menentukan tujuan karier yang realistis, serta merancang langkahlangkah untuk mencapai tujuan secara sistematis. Materi goal setting dalam pelatihan ini memungkinkan siswa untuk belajar mengetahui serta mengidentifikasi potensi hambatan yang akan muncul dalam proses pencapaian tujuan.

Efikasi diri merupakan keyakinan yang melibatkan proses psikologis, di mana proses ini berperan penting dalam perubahan perilaku pada individu (Baglama \& Uzunboylu, 2017). Menurut Komarraju \& Nadler (2013) efikasi diri berkaitan baik dengan pengalaman masa lampau, maupun dengan ekspektasi pencapaian akademik di masa depan. Pelatihan perencanaan karier penting dilakukan, karena individu dengan efikasi diri yang tinggi dilaporkan dapat menunjukkan upaya yang lebih persisten dalam mengatasi kesulitan. Sebaliknya, individu yang memiliki efikasi diri tidak adekuat cenderung menghindari kesulitan, dan cenderung menghindar dari tanggung jawab (Bolat \& Odaci, 2017).

Keterbatasan penelitian ini terletak pada tidak dilakukannya follow-up terhadap partisipan setelah posttest, sehingga penelitian ini hanya dapat melihat efek pelatihan dalam jangka waktu pendek saja. Follow-up menjadi pertimbangan yang penting untuk dilakukan agar dapat mengetahui apakah peningkatan yang dicapai oleh partisipan penelitian selama proses pelatihan dapat bertahan atau tidak. Hal tersebut didasarkan pada pendapat Martin \& Pear (2003) yang menyatakan bahwa sebuah permasalahan dapat dikatakan selesai apabila skor peningkatan dapat bertahan. Keterbatasan yang lain adalah pelatihan ini dilaksanakan pada pekan remidial setelah ujian akhir semester dan bersamaan dengan kegiatan class-meeting, sehingga waktu pelaksanaan pada hari kedua tidak sesuai dengan jadwal yang telah direncanakan. Selain itu, terdapat beberapa siswa yang terpaksa meninggalkan pelatihan selama 30 menit untuk mewakili kelas dalam perlombaan class-meeting.

\section{Kesimpulan}

Hasil analisis data menunjukkan bahwa Pelatihan Perencanaan Lanjut Studi (PLANS) dapat meningkatkan efikasi diri dalam pengambilan keputusan karier pada siswa kelas IX Sekolah Menengah Pertama (SMP). Hasil analisis menunjukkan bahwa kelompok eksperimen memiliki peningkatan efikasi diri dalam pengambilan keputusan karier secara signifikan dibandingkan kelompok kontrol. Partisipan dalam kelompok eksperimen juga memiliki peningkatan pengetahuan mengenai perencanaan karier dibandingkan kelompok kontrol.

Pelatihan Perencanaan Lanjut Studi (PLANS) efektif dalam meningkatkan efikasi diri dalam pengambilan keputusan karier pada siswa kelas IX Sekolah Menengah Pertama (SMP) karena dalam pelatihan ini menggunakan metode belajar observational learning yang terdiri atas empat fase pembelajaran, yakni attentional phase, retention phase, production phase, dan motivational phase. Melalui metode observational learning ini, 
individu memperoleh keterampilan kognitif serta perilaku baru melalui pengamatan terhadap performansi orang lain.

Saran

Pelatihan Perencanaan Lanjut Studi ini terbukti dapat meningkatkan efikasi diri dalam pengambilan keputusan karier bagi siswa kelas IX Sekolah Menengah Pertama (SMP). Oleh karena itu, sekolah dapat memberikan konseling wawasan karier kepada siswa, baik dengan memasukkan program tersebut ke dalam program guru $\mathrm{BK}$, maupun dengan menjalin kerja sama dengan pihak yang kompeten, seperti misalnya psikolog sekolah. Orang tua juga perlu mendapatkan edukasi terkait wawasan karier agar mereka dapat membantu mengarahkan anak untuk dapat memilih jurusan serta karier yang sesuai dengan kepribadian dan kemampuan anak, serta dapat disesuaikan dengan peluang yang ada.

Peneliti selanjutnya dapat melakukan replikasi dengan mengatasi kelemahan pada penelitian ini. Penelitian ini juga dapat dikembangkan dengan mengambil kriteria subjek yang berbeda, misalnya siswa yang berasal dari latar belakang keluarga menuju sejahtera, maupun subjek dengan skor efikasi diri dalam pengambilan keputusan karier yang rendah.

\section{Kepustakaan}

Ardiyanti, D., \& Alsa, A. (2015). Pelatihan "PLANS" untuk meningkatkan efikasi diri dalam pengambilan keputusan karier. Gadjah Mada Journal of
Professional Psychology (GamaJPP), 1(1), $1-17$.

Ardiyanti, D. (2014). Pelatihan "PLANS" untuk meningkatkan efikasi diri dalam pengambilan keputusan karier pada siswa SMA (Tesis tidak dipublikasikan). Yogyakarta: Universitas Gadjah Mada.

Atanda, R. (1999). Statistics in brief: Do gatekeeper courses expand education options? Washington DC: U.S. Department of Education, National Center for Education Statistics.

Baglama, B., \& Uzunboylu, H. (2017). The relationship between career decisionmaking self-efficacy and vocational outcome expectations of preservice special education teachers. South African Journal of Education, 37(4), 1-11. doi: 10.15700/saje.v37n4a1520

Bandura, A. (1997). Self-efficacy: The exercise of control. New York: W. H. Freeman and Company.

Beghetto, R. A. (2006). Creative self-efficacy: Correlates in middle and secondary students. Creativity Research Journal, 18(4), 447-457. doi:

\subsection{7/s15326934crj1804 4}

Betz, N. E., \& Wolfe, J. B. (2005). Measuring confidence for basic domains of vocational activity in high school students. Journal of Career Assessment, 13(3), 251-270. doi: 10.1177/1069072705274951

Bolat, N., \& Odaci, H. (2017). High school final year students' career decisionmaking self-efficacy, attachment styles and gender role orientations. Current 
Psychology, 36, 252-259. doi: 10.1007/s12144-016-9409-3

Damayanti, D., \& Widyowati, A. (2018). Peningkatan Career Decision Making SelfEfficacy (CDMSE) melalui Pelatihan Perencanaan Karier pada siswa SMK. Humanitas, 15(1), 35-45. doi: $\underline{10.26555 / h u m a n i t a s . v 15 i 1.7409}$

Gibbsons, M. M., \& Borders, L. D. (2010). A measure of college-going self-efficacy for middle school students. Professional School Counseling, 13(4), 234-244. doi: 10.1177/2156759X1001300404

Jaffe, D. T., \& Scott, C. D. (1991). Career development for empowerment in a changing work world. In J. M. Kummerow (Ed.), New directions in career planning and the workplace. Practical strategies for counselors (hal. 3359). California: CPP Books.

Kementerian Riset, Teknologi, dan Pendidikan Tinggi Republik Indonesia (Kemenristekdikti). (2018, April 3). Perusahaan rintisan inkubasi Kemenristekdikti "Youthmanual" bantu siswa memilih jurusan kuliah sesuai potensi secara online. Diakses melalui ristekdikti.go.id/siaranpers/perusahaan-rintisan-inkubasikemenristekdikti-youthmanual-bantusiswa-memilih-jurusan-kuliah-sesuaipotensi-secara-online/

Komarraju, M., \& Nadler, D. (2013). Selfefficacy and academic achievement: Why do implicit beliefs, goals, and effort regulation matter? Learning and Individual Differences, 25, 67-72. doi: 10.1016/j.lindif.2013.01.005
Kudo, H., \& Mori, K. (2015). A preliminary study of increasing self-efficacy in junior high school students: Induced success and a vicarious experience. Psychological Reports, 117(2), 631-642. doi: $10.2466 / 11.07 . P R 0.117 \mathrm{c} 22 \mathrm{z} 4$

Leigh, D. (2006). The group trainer's handbook: Designing and delivering training for groups (Edisi ketiga). London: Kogan Page.

Martin, G., \& Pear, J. (2003). Behavior modification: What it is and how to do it. New York: Prentice Hall.

Reddan, G. (2015). Enhancing students' selfefficacy in making positive career decision. Asia-Pacific Journal of Cooperative Education, 16(4), 291-300.

Salas, E., \& Bowers, C. J. (2001). The science of training: A decade of progress. Annual Review Psychology, 52, 471-499. doi: 10.1146/annurev.psych.52.1.471

Seo, Y., \& Jeong C. (2016). Effect of career coaching program for career decision making self efficacy, self-leadership, and employment-stress of nursing students'. Journal of the Korea AcademiaIndustrial Cooperation Society, 17(2), 138145. doi: 10.5762/KAIS.2016.17.12.138

Storme, M., \& Celik, P. (2018). Career exploration and career decision-making difficulties: The moderating role of creative self-efficacy. Journal of Career Assessment, 26(3), 445-456. doi: $\underline{10.1177 / 1069072717714540}$

Su, M. S., Chang, T. C., Wu, C. C., \& Liao, C. W. (2016). Factors affecting the students career decision-making of junior high school students in Central Taiwan Area. 
International Journal of Information and Education Technology, 6(11), 843-850. doi: 10.18178/ijiet.2016.V6.803

Sudira, P. (2013). Pre-vocational courses on primary education. Yogyakarta: Universitas Negeri Yogyakarta.
Wang, J., Zhang, D., \& Shao, J. (2010). Group training on the improvement of college students' career decision-making selfefficacy. Health, 2(6), 551-556. doi: 10.4236/health.2010.26082 
Tabel 1.

Blueprint Pelatihan "PLANS"

\begin{tabular}{|c|c|c|c|c|}
\hline Sesi & Tujuan & Aktivitas & Waktu & $\begin{array}{c}\text { Proses } \\
\text { Observational } \\
\text { Learning }\end{array}$ \\
\hline $\begin{array}{l}\text { Sesi I: Analisis } \\
\text { Diri }\end{array}$ & $\begin{array}{l}\text { - Agar peserta memiliki } \\
\text { gambaran umum tentang } \\
\text { tahapan perencanaan } \\
\text { karir. }\end{array}$ & $\begin{array}{l}\text { - Games pemahaman } \\
\text { diri } \\
\text { - Penugasan individu: } \\
\text { memahami diri } \\
\text { - } \text { Refleksi diri }\end{array}$ & 75 menit & $\begin{array}{l}\text { Attention } \\
\text { Retention }\end{array}$ \\
\hline $\begin{array}{l}\text { Sesi II: } \\
\text { Wawasan Karir }\end{array}$ & $\begin{array}{l}\text { - Agar peserta paham } \\
\text { tentang pentingnya } \\
\text { melakukan eksplorasi } \\
\text { karir sebelum } \\
\text { mengambil keputusan. } \\
\text { - Agar peserta mengetahui } \\
\text { sumber-sumber } \\
\text { informasi program studi. } \\
\text { - Agar peserta mengetahui } \\
\text { berbagai informasi dan } \\
\text { peluang program studi } \\
\text { di perguruan tinggi, } \\
\text { termasuk prospek karir } \\
\text { dari program studi. }\end{array}$ & $\begin{array}{l}\text { - Energizer } \\
\text { - Games kotak misteri } \\
\text { - Pemaparan kasus dan } \\
\text { diskusi } \\
\text { - Informasi program } \\
\text { studi } \\
\text { - Refleksi diri } \\
\text { - Kuis tebak profesi }\end{array}$ & 150 menit & $\begin{array}{l}\text { Attention } \\
\text { Retention }\end{array}$ \\
\hline $\begin{array}{l}\text { Sesi III: } \\
\text { Penetapan } \\
\text { Tujuan dan } \\
\text { Perencanaan } \\
\text { Karir }\end{array}$ & $\begin{array}{l}\text { - Agar peserta mampu } \\
\text { menetapkan tujuan atau } \\
\text { targetnya terkait } \\
\text { program studi. } \\
\text { - Agar peserta mampu } \\
\text { menganalisis masalah } \\
\text { yang mungkin timbul } \\
\text { dan rencana problem } \\
\text { solvingnya. } \\
\text { - Agar peserta mampu } \\
\text { membuat suatu } \\
\text { perencanaan yang detail, } \\
\text { sistematis, dan terukur. } \\
\text { - Agar peserta mampu } \\
\text { membuat dan } \\
\text { memahami rencana } \\
\text { jangka pendek dan } \\
\text { jangka panjang. }\end{array}$ & $\begin{array}{l}\text { - } \text { Games penetapan } \\
\text { tujuan } \\
\text { - } \quad \text { Pemaparan tentang } \\
\text { goal setting yang } \\
\text { SMART dan video } \\
\text { target } \rightarrow \text { sebagai } \\
\text { contoh atau inspirasi } \\
\text { tujuan yang SMART } \\
\text { - Penugasan Individu: } \\
\text { perencanaan karir } \\
\text { - } \quad \text { Refleksi diri }\end{array}$ & 90 menit & $\begin{array}{l}\text { Attention } \\
\text { Retention }\end{array}$ \\
\hline
\end{tabular}




\begin{tabular}{|c|c|c|c|c|}
\hline $\begin{array}{l}\text { Sesi IV: } \\
\text { Rencana } \\
\text { Tindakan }\end{array}$ & $\begin{array}{l}\text { Agar peserta memahami } \\
\text { bagaimana memastikan } \\
\text { rencana pencapaian } \\
\text { tujuan dapat terlaksana } \\
\text { melalui pelaksanaan } \\
\text { yang terjadwal. }\end{array}$ & $\begin{array}{ll}\text { - } & \text { Membuat jadwal } \\
\text { rencana tindakan } \\
\text { - } & \text { Refleksi diri }\end{array}$ & 30 menit & $\begin{array}{l}\text { Attention } \\
\text { Retention }\end{array}$ \\
\hline Sesi V: Evaluasi & $\begin{array}{l}\text { - Agar peserta paham } \\
\text { pentingnya suatu } \\
\text { evaluasi. } \\
\text { - Agar peserta dapat } \\
\text { mengevaluasi pilihan } \\
\text { dan rencana } \\
\text { tindakannya. }\end{array}$ & $\begin{array}{ll}\text { - } & \text { Evaluasi hasil } \\
& \text { keputusan dan } \\
& \text { rencana tindakan } \\
\text { - } & \text { Gambaran perasaan } \\
\text { - } & \text { Refleksi diri }\end{array}$ & 40 menit & $\begin{array}{l}\text { Attention } \\
\text { Retention }\end{array}$ \\
\hline Penutupan & $\begin{array}{l}\text { - Agar peserta mampu } \\
\text { menyimpulkan isi materi } \\
\text { pelatihan. } \\
\text { - Mengetahui pendapat } \\
\text { peserta tentang } \\
\text { pelaksanaan kegiatan } \\
\text { pelatihan. }\end{array}$ & $\begin{array}{l}\text { - Penugasan akhir: } \\
\text { menulis perencanaan } \\
\text { karir diri “My Plan" } \\
\text { dan presentasi } \\
\text { - Kesimpulan pelatihan } \\
\text { - Kesan dan evaluasi } \\
\text { dari peserta tentang } \\
\text { pelatihan }\end{array}$ & 100 menit & $\begin{array}{l}\text { Production } \\
\text { Motivational }\end{array}$ \\
\hline
\end{tabular}

